\title{
Rainfall Intensities for Buried Municipal Stormwater System
}

Design

\author{
Yi Wang and Edward A. McBean \\ University of Guelph, Guelph, Ontario.
}

Received 2014-05-05, accepted 2015-04-27, published 2015-10-15.

\begin{abstract}
Heavy rainfall events are likely to be more frequent and intensive as climate change occurs. For urban infrastructure, design rainfall intensities are important since they may change, and involve considerable uncertainty in their assignments. Selection of frequency distribution is assessed, and the Gumbel distribution is demonstrated as appropriate for modeling the annual maximum series (AMS) of rainfall records. However, a rainfall model using partial duration series (PDS) is demonstrated to be suitable for events with recurrence intervals $<10 \mathrm{y}$, compared to the AMS model. Statistically significant changes in design rainfall intensities are evidenced, with the identified changes being sensitive to the period of record used. A regional L-moment algorithm is recommended for reducing uncertainties involved in design rainfall intensity estimates, and an example of $1 \mathrm{~h}$ duration rainfall at Kingston, Ontario is provided as a case study.
\end{abstract}

\section{Introduction}

Increasing amounts of greenhouse gases in the atmosphere are leading to global warming, and contributing to more intensive climate extremes, such as minimum daily temperatures or heavy hourly rainfall quantities that occur every 5 y on average (Frei et al. 2006; Fowler and Kilsby 2003; Zhai et al. 1999). Thus if heavy rainfall events are likely to change, it is appropriate to evaluate design rainfall intensities pertinent to municipal stormwater system design. Heavy rainfall refers to rainfall events with return periods between $2 \mathrm{y}$ and $10 \mathrm{y}$.

Heavy events in rainfall records are extracted as data series to develop a rainfall intensity model. The series with all data values above a selected threshold is referred to as the partial duration series (PDS), and the group of all largest values from each year is referred to as the annual maximum series (AMS). The Atmospheric Environment Service of Environment Canada developed heavy rainfall intensity models using AMS data and the Gumbel distribution (Hogg et al. 1989). The Ontario Ministry of Transportation (MTO) provides intensity-duration-frequency (IDF) curves, using the Gumbel distribution as an extreme value probability density function. Given that the Gumbel distribution is a two-parameter distribution, this limits the performance when compared to various three-parameter distributions such as the generalized extreme value (GEV) distribution, the generalized Pareto (GPA) distribution or the Pearson type 3 (PE3) distribution.
Of interest is to determine the most appropriate frequency distribution to model heavy rainfall intensities.

The uncertainties involved in design rainfall intensity estimates are substantial since models necessarily rely upon limited rainfall records (Coles et al. 2003; García-Ruiz et al. 2000). The difference between the expected value and $95 \%$ confidence limits can be as large as $25 \%$ of the expected value, which increases the risks of stormwater system failure to cope when assigning the expected value as the design rainfall intensity (Aronica et al. 2005; Semadeni-Davies et al. 2008). The relationship between the uncertainty in rainfall intensity estimates and the record length is characterized to find the circumstances under which a rainfall record can produce accurate design rainfall intensity estimates.

Rainfall intensity models frequently employ AMS data to estimate the probability of a given value being exceeded. An AMS model focuses on the largest event in a year, ignoring the second and third largest values in the same year (Laurenson, 1987). The AMS model cannot model probabilities for the situation when more than one rainfall event exceeds the predicted rainfall intensity in the same year, which indicates potential street flooding or basement flooding, from an urban storm water management perspective. On the contrary, the rainfall intensity model using PDS data estimates the probability of a storm event exceeding the design rainfall intensity. The resulting PDS model approach has significant advantages in comparison with the AMS model.

Wang, Yi and Edward A. McBean. 2015. "Rainfall Intensities for Buried Municipal Stormwater System Design.” Journal of Water Management Modeling C393. doi:10.14796/JWMM.C393.

c) CHI 2015. www.chijournal.org ISSN 2292-6062. 
If use of a PDS model is appropriate for evaluating design rainfall intensities, the timeframe of the historical rainfall record needs to be examined as well. It follows that the use of the entire record, regardless of the length of and which time period it is covering, is not always appropriate. A very long record may involve temporal changes, since the climate when a rainfall record was recorded may include substantial differences from the most recent climate (Zhang et al. 2001; Burn and Taleghani 2013; Vincent and Mekis 2006). Therefore an analysis of the design rainfall intensity changes, versus the timeframe of the historical rainfall record used, is needed. This can be examined by splitting the rainfall records into two approximately equal lengths of record to estimate design rainfall intensities separately and then comparing them, to detect if changes are evident. The time of splitting may be enumerated over a range of years to identify the sensitivity of design rainfall intensity changes in response to the split year.

For design rainfall intensity estimates where substantial uncertainties exist (i.e. a large magnitude of confidence interval) due either to climate change effects or limited rainfall records, grouping with adjacent rainfall stations and using regional frequency analyses is an alternative to reduce the uncertainties involved in estimating design rainfall intensities (Ngongondo et al. 2011; Sveinsson et al. 2002). A regional L-moment algorithm averages the statistical characteristics of rainfall records within a group, which is assumed (and tested) for statistical similarity, and evaluates the design rainfall intensities of each station in the group based on regional growth curves and an at-site scale factor (Hosking and Wallis 1997). The regional L-moment algorithm is applied herein to rainfall records in Southern Ontario to demonstrate the reduction of uncertainties involved in characterizing intensities of design rainfalls.

This study uses rainfall records from climate stations in Ontario to examine the issues and techniques introduced above. The principal research objective is to improve the understanding of design rainfall intensities pertinent to municipal stormwater system design, and follows the lines of:

- investigating the use of the Gumbel distribution with AMS data;

- analysing the uncertainties involved in the AMS model and related IDF curves;

- investigating the advantages of using PDS instead of AMS in rainfall intensity modeling;

- identifying changes in design rainfall intensity in respect to the timeframe of the historical rainfall record; and

- assessing the potential of the regional L-moment algorithm for reducing uncertainties in design rainfall intensities.

The data obtained from Environment Canada were recorded over the period 1960-2007, with record lengths ranging from $1 \mathrm{y}$ to $65 \mathrm{y}$, and an average of $13 \mathrm{y}$. The rainfall records include daily maximum rainfall amounts over durations of $5 \mathrm{~min}, 10 \mathrm{~min}$, $15 \mathrm{~min}$ and $30 \mathrm{~min}$, and $1 \mathrm{~h}, 2 \mathrm{~h}, 6 \mathrm{~h}$ and $12 \mathrm{~h}$. Only rainfall records between April and October are employed, and annual records missing more than $20 \%$ were excluded. The following analyses use different subsets of these rainfall records.

\section{The Gumbel Distribution Is Appropriate}

Gumbel (1954) developed an easy method to apply the Fisher-Tippett Type 1 distribution (Fisher and Tippett 1928), and this method is commonly referred to as the Gumbel distribution. The CDF and quantile functions of the Gumbel distribution are as in Equations 1 and 2.

$$
\begin{aligned}
& F(x)=\exp \left(-\exp \left(-\frac{x-\xi}{\alpha}\right)\right) \\
& x(F)=\xi-\alpha \log (-\log (F))
\end{aligned}
$$

where:

$$
\begin{aligned}
& x= \text { quantile with non-exceedance probability of } \mathrm{F} \text {, and } \\
& a, \xi= \text { scale and location parameters respectively, and } \\
& \text { are estimated by sample L-moments } I_{1} \text { and } I_{2^{\prime}} \text { as } \\
& \text { in Equation } 3 . \\
& \hat{\alpha}=\frac{l_{2}}{\log 2}, \hat{\xi}=l_{1}-\gamma \hat{\alpha}
\end{aligned}
$$

where:

$$
\gamma=0.5772 \text {, Euler's constant. }
$$

Several methods can be used to assess the performance of a statistical distribution, when fitted to a rainfall record, including the plotting position correlation coefficient (PPCC, after Filliben 1975) method, the Anderson-Darling test (Anderson and Darling 1954), the L-moment ratio diagram (Hosking and Wallis 1997), and the relative root mean square error (rRMSE, Hosking and Wallis 1997). The first three methods all analyse the fitness for the entire dataset, while the last method only focuses on event estimates of a specific return period. This paper uses the L-moment ratio diagram to select distribution candidates and then uses the rRMSE to assess the performance of candidates on event estimates of return periods of $2 \mathrm{y}, 5 \mathrm{y}, 10 \mathrm{y}$ and $25 \mathrm{y}$. This section uses historical rainfall records for 21 climate stations with $40 \mathrm{y}$ of record.

In Figure 1, the L-moment ratios of data from 21 stations (rainfall durations of $5 \mathrm{~min}, 10 \mathrm{~min}, 15 \mathrm{~min}, 30 \mathrm{~min}, 1 \mathrm{~h}$ and $2 \mathrm{~h}$ ) are indicated as circles, together with squares representing distributions of Gumbel (G), exponential (E), normal (N), logistic $(\mathrm{L})$, uniform $(\mathrm{U})$, and curves representing three-parameter distributions of generalized logistic (GLO), generalized extreme value (GEV), generalized Pareto (GPA), generalized normal (GNO), and Pearson type 3 (PE3). From the L-moment ratio diagram, the probability distributions of $\mathrm{L}, \mathrm{N}, \mathrm{U}, \mathrm{E}, \mathrm{GLO}$, and GPA are excluded because they deviate from the bulk of the circles. The acceptable candidate distributions include G, GEV, GNO, and PE3. In addition, the three-parameter log-normal (LN3) distribution is close to the centre of the circles in Figure 2 after log-transforming the original data, and is added to the candidate distribution set as well. 


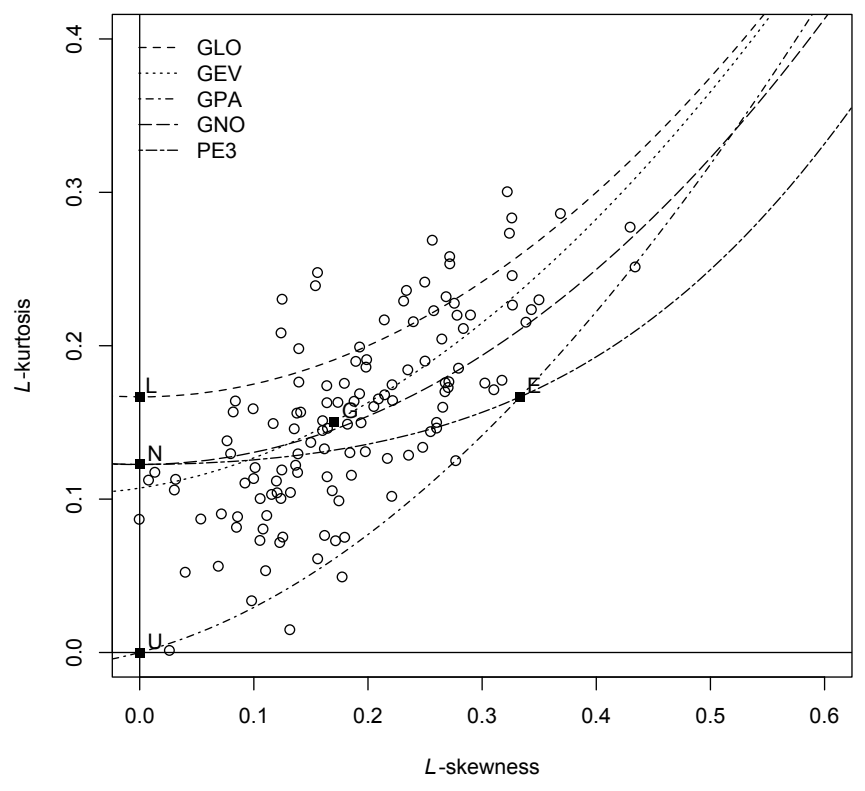

Figure 1 L-moment ratio diagram for rainfall records.

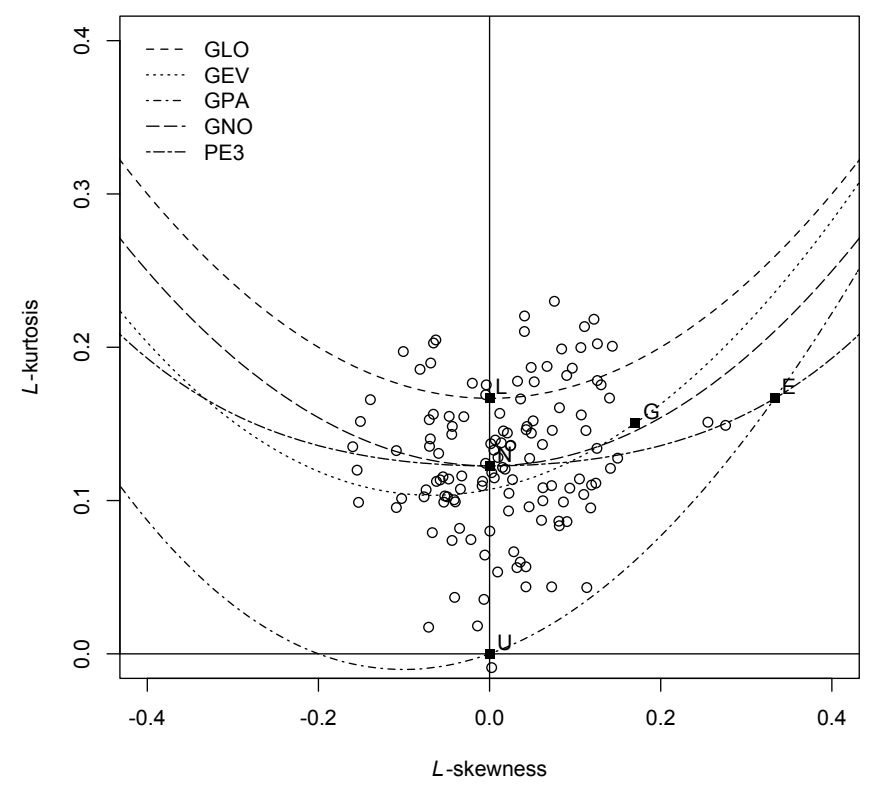

Figure 2 L-moment ratio diagram for log-transformed values.

The rRMSE method is implemented using Monte Carlo simulation. With distribution parameters estimated from the original sample set, $M$ realizations of sample sets are produced and fitted with the same frequency distribution. The rRMSE for non-exceedance probability $F$ is then computed from $M$ estimates of the quantile, using Equation 4.

$$
R(F)=\left[M^{-1} \sum_{m=1}^{M}\left\{\frac{Q^{[m]}(F)-Q(F)}{Q(F)}\right\}^{2}\right]^{1 / 2}
$$

Figure 3 below shows rRMSE for estimates of $2 y, 5 y, 10 y$ and $25 \mathrm{y}$ return periods. In each plot, the rRMSEs of all 21 stations for the same rainfall duration are pooled together as box plots to show the range and central tendency of the rRMSE. Box plots of five candidate distributions are drawn side-by-side for visual comparison. Amongst the box plots for all four return periods and six rainfall durations, all candidates show similar performance. The Gumbel distribution has larger ranges of errors than other candidates for 2 y event estimates, but also has a smaller mean error for $25 \mathrm{y}$ event estimates. The errors of all candidates show no apparent differences for $5 \mathrm{y}$ and $10 \mathrm{y}$ event estimates. These results demonstrate that the Gumbel distribution is as appropriate as the three-parameter distributions for the performance characterization of predicting design rainfall intensities, and is simpler in computation (two-parameter distribution); on these bases, it is reasonable to continue using the Gumbel distribution to model AMS data.

\section{Uncertainties in Design Rainfall Intensity Estimates}

The uncertainties involved in design rainfall intensity estimates can be characterized by confidence intervals or by the ratio of the confidence interval to the estimated design value. In Ontario, two major sources of IDF curves are available. The Meteorological Service of Canada (MSC) of Environment Canada provides data files including IDF interpolation equations and return period rainfall rates with $95 \%$ confidence intervals for 133 climate stations, and was last updated in 2012. The MTO provides online lookup tools for IDF curve interpolation coefficients and rainfall intensity estimates with $95 \%$ confidence intervals for selected durations, and provides comparisons with MSC data files as well (added in Fall 2013).

The design rainfall intensities and related uncertainties are publicly accessible with the work of MSC and MTO; however, caution is still needed. It is not always appropriate to use the best estimate of the design rainfall intensity, especially when the uncertainty associated with the estimate is considerable, i.e. the confidence interval is large. For example, at Waterloo Wellington Airport (climate station ID 6149387), the upper confidence limit of the $25 \mathrm{y}$ design rainfall estimate is very close to the expected value of the $100 \mathrm{y}$ event estimate (Table 1), which means the 100 y event estimate may be a $25 \mathrm{y}$ event in reality.

Table 1 Selected expected values and upper limits of design rainfall intensity at Waterloo Wellington Airport.

\begin{tabular}{lccc}
\hline Durations & \multicolumn{2}{c}{$25 \mathrm{y}$ Event Intensity $(\mathrm{mm} / \mathrm{h})$} & $\begin{array}{c}100 \mathrm{y} \text { Event Intensity }(\mathrm{mm} / \mathrm{h}) \\
\text { Expected Value }\end{array}$ \\
\hline $30 \mathrm{~min}$ & 79.5 & 96.3 & 98.9 \\
$1 \mathrm{~h}$ & 55.5 & 68.8 & 70.9 \\
$2 \mathrm{~h}$ & 32.9 & 40.7 & 41.9 \\
\hline
\end{tabular}

Wang and McBean (2013) reported a linear relationship between the uncertainty and the log-transformed record length. 

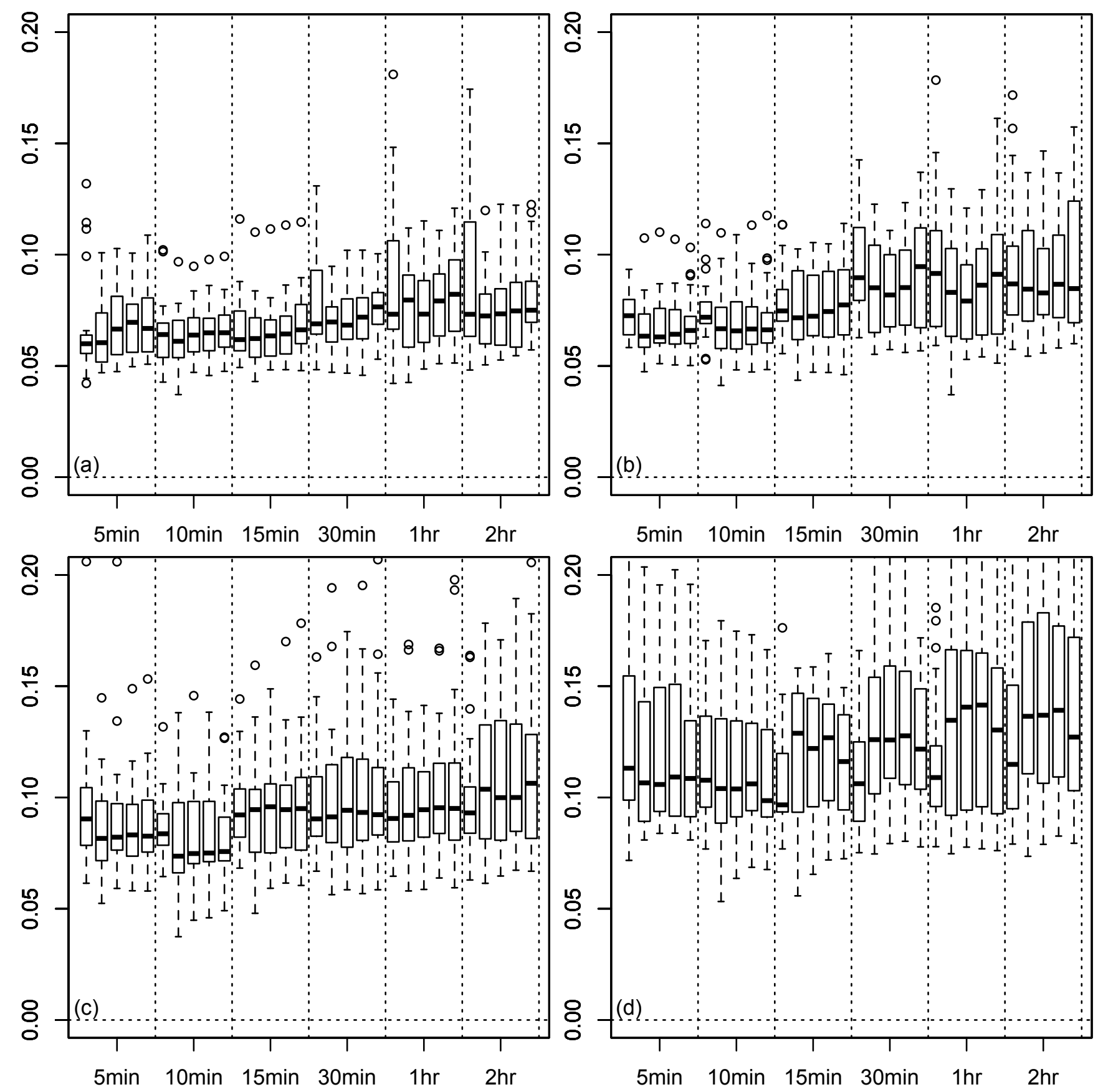

Figure 3 Boxplot of the relative RMSE of the candidate distributions; in each plot, the boxes of five candidates are delineated by dotted lines (the five candidates are: G, LN3, GEV, GNO and PE3, from left to right); return Periods are: (a) 2 y, (b) 5 y, (c) 10 y, (d) 25 y.

Using this linear relationship, one can predict the length of record needed to decrease uncertainties to a specific level. For example, the record length needed to estimate a 95\% confidence interval as $\pm 10 \%$ of the expected value is $62 \mathrm{y}$, for the $25 \mathrm{y}$ return, $1 \mathrm{~h}$ rainfall intensity estimate at Kingston (climate station ID 6104146).
Given that Kingston only has $45 y$ of rainfall record, $\pm 10 \%$ uncertainty of the expected value cannot be obtained.

In cases when the design rainfall intensity estimate involves sizable uncertainty (e.g. $> \pm 10 \%$ ), use of the upper confidence limit instead of the expected value of the design rainfall intensity should be considered. 


\section{Use of Partial Duration Series Is Appro- priate}

The PDS model estimates average recurrence intervals between storm events exceeding a given value, or the threshold intensity with a desired return period. A PDS model analyzes the return periods between storm events, while the AMS model focuses on the return period between years in which a given rainfall intensity is exceeded.

The difference between the estimates from the two models is considerable when the return period is $<10 \mathrm{y}$, because the possibility of such events occurring more than once in a year is not negligible. Examples when the $5 \mathrm{y}$ design rainfall intensity is exceeded twice or more in a year in Ontario include at Owen Sound (climate station ID 6116132) in 1968. The $1 \mathrm{~h} 5 \mathrm{y}$ return period rainfall intensity is given as $34.5 \mathrm{~mm} / \mathrm{h}$ from MSC data files, and estimated from the PDS model as $36.3 \mathrm{~mm} / \mathrm{h}$. As shown in Figure 4, two events exceeded this intensity: $43.9 \mathrm{~mm} / \mathrm{h}$ on August 19th and $38.9 \mathrm{~mm} / \mathrm{h}$ on August 22nd, and both are more intensive than the maximum in the year 1969. Similarly, at Chatham (climate station ID 6131415) in 1967, the MSC $1 \mathrm{~h} 5$ y rainfall intensity is $35.7 \mathrm{~mm} / \mathrm{h}$ and two events exceeded this intensity: 49.8 $\mathrm{mm} / \mathrm{h}$ on June 28 th and $52.3 \mathrm{~mm} / \mathrm{h}$ on July $31 \mathrm{st}$. The PDS model estimate of the same return period is $37.4 \mathrm{~mm} / \mathrm{h}, 5 \%$ greater than the estimate from the AMS model. Further, the MSC design value $(35.7 \mathrm{~mm} / \mathrm{h}$ ) has an average recurrence interval of $4.1 \mathrm{y}$ in the PDS model.

In these examples, the second largest events in individual years are excluded from the AMS model; however, the PDS model uses all rainfall intensities exceeding a selected threshold. Besides, with a larger design rainfall intensity estimate from the PDS model, the stormwater system has higher capacity to drain stormwater in cases of heavy rainfall events. Stormwater system design for heavy rainfall events should use the PDS model instead of the AMS model.

\section{Changes in Design Rainfall Intensities}

To analyze changes in design rainfall intensities with respect to the timeframe of the rainfall record, design rainfall intensities estimated from records of two consecutive time periods (1960-1983 and 1984-2007) are compared, based on $1 \mathrm{~h}$ rainfall records from 34 climate stations in Southern Ontario. The confidence intervals are computed using the resampling method (Douglas et al. 2000; Burn and Hag Elnur 2002; Adamowski and Bougadis 2003). If the confidence intervals for the design rainfall intensity of the same return period do not overlap, then a step change in the design rainfall intensity is identified, with statistical significance no less than the confidence level. Further, the changing rates of the design rainfall intensity are calculated, as in Equation 5.

$$
\frac{\left(i_{2}-i_{1}\right) / i_{1}}{t_{2}-t_{1}} \times 100 \%
$$

where:

$$
\begin{aligned}
& i_{1^{\prime}}, i_{2}=\begin{array}{l}
\text { design rainfall intensities estimated from two } \\
\text { time periods, separately, and }
\end{array} \\
& t_{1^{\prime}} t_{2}=\text { the mid-point years of these two time periods. } \\
& \text { Table } 2 \text { lists the results for all } 34 \text { stations, for changes in }
\end{aligned}
$$
design rainfall intensities of $2 y, 5 y, 10 y$ and $25 y$ return periods.

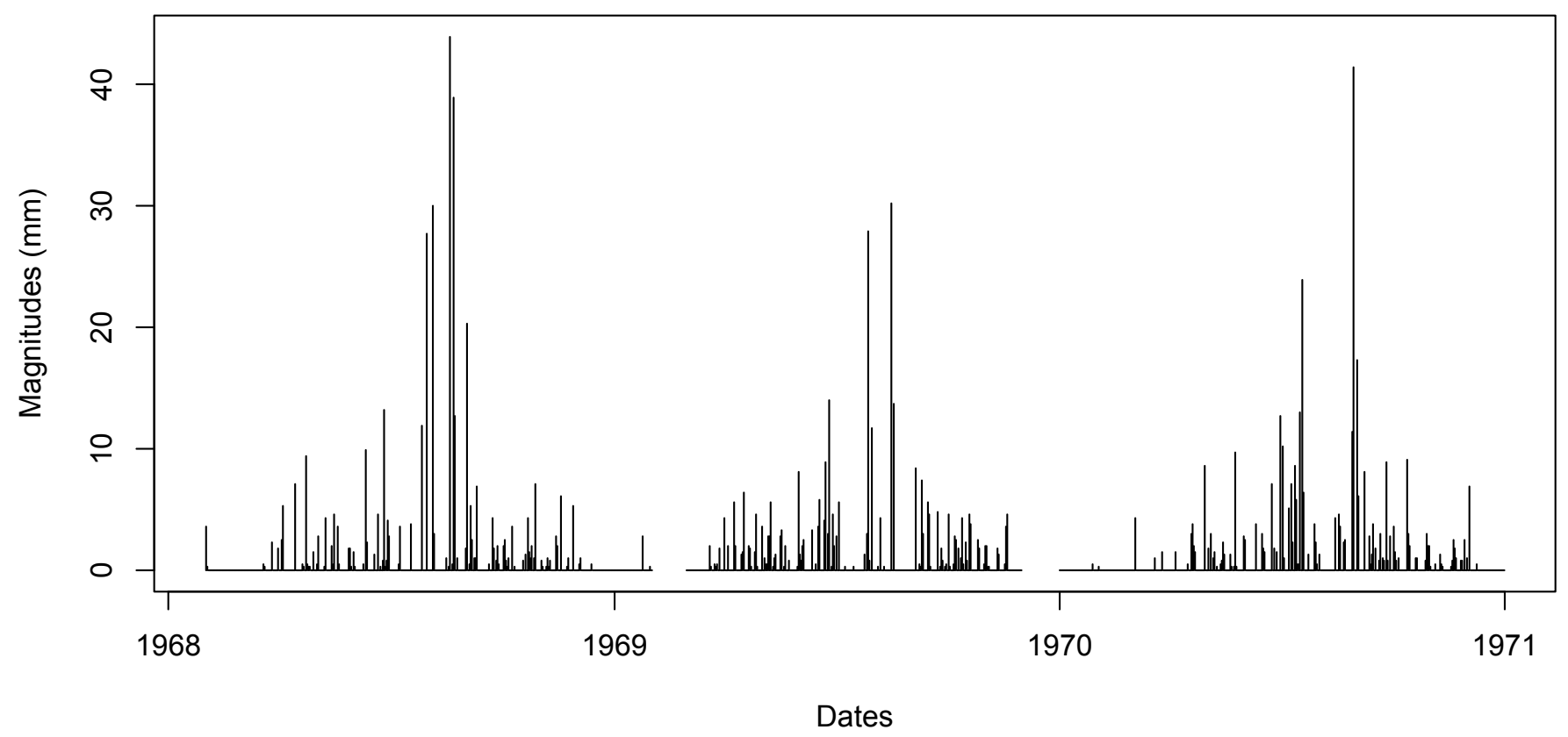

Figure 4 Daily maximum $1 \mathrm{~h}$ rainfall record at Owen Sound (1968-1970). 
Approximately half of the climate stations show increases in design rainfall intensities, while half show decreases; only a few of these changes are statistically significant at $80 \%$ (marked with asterisks).

Table 2 Annual changing rate of design rainfall intensities in Southern Ontario.

\begin{tabular}{|c|c|c|c|c|c|}
\hline $\begin{array}{c}\text { Climate } \\
\text { Station ID }\end{array}$ & Station Name & 2 Years & 5 Years & 10 Years & 25 Years \\
\hline 6100971 & BROCKVILLE PCC & 0.07 & -0.29 & -0.65 & -1.17 \\
\hline 6104027 & KEMPTVILLECS & 0.78 & 0.96 & 1.01 & 1.00 \\
\hline 6104175 & KINGSTON PUMPING STATION & -0.07 & 0.18 & 0.40 & 0.75 \\
\hline 6105978 & OTTAWA CDA RCS & $-0.89^{*}$ & -0.83 & -0.70 & -0.45 \\
\hline 6106000 & OTTAWA MACDONALD-CARTIER INT'L A & $-1.40^{*}$ & $-1.15^{*}$ & -0.90 & -0.50 \\
\hline 6127514 & SARNIA AIRPORT & 0.64 & 1.02 & 1.36 & 1.88 \\
\hline 6131415 & СНАТНАM WPCP & -0.50 & $-1.10^{*}$ & $-1.52^{*}$ & $-2.01^{*}$ \\
\hline 6131983 & DELHICS & $0.97^{*}$ & $1.75^{*}$ & $2.38^{*}$ & $3.25^{*}$ \\
\hline 6133362 & HARROW CDA AUTO & 0.66 & 0.49 & 0.29 & -0.03 \\
\hline 6136606 & PORT COLBORNE & -0.06 & 0.44 & 0.96 & 1.78 \\
\hline 6137287 & ST CATHARINES A & -0.46 & -1.19 & -1.72 & -2.36 \\
\hline 6137362 & ST THOMAS WPCP & 0.13 & 0.00 & -0.13 & -0.33 \\
\hline 6139148 & VINELAND STATION RCS & -0.62 & -0.67 & -0.72 & -0.78 \\
\hline 6139525 & WINDSOR A & $-0.61^{*}$ & -0.52 & -0.43 & -0.30 \\
\hline 6140954 & BRANTFORD MOE & -0.07 & -0.27 & -0.32 & -0.3 \\
\hline 6142400 & FERGUS SHAND DAM & 0.03 & -0.15 & -0.30 & -0.50 \\
\hline 6144478 & LONDONCS & -0.03 & -0.22 & -0.36 & -0.55 \\
\hline 6146714 & PRESTON WPCP & $2.62^{*}$ & $2.81^{*}$ & $2.78^{*}$ & 2.60 \\
\hline 6148105 & STRATFORD MOE & 0.35 & 0.60 & 0.89 & 1.37 \\
\hline 6149387 & WATERLOO WELLINGTON A & $1.63^{*}$ & 2.00 & 2.30 & 2.73 \\
\hline 6150689 & BELLEVILLE & $1.09^{*}$ & $1.28^{*}$ & $1.44^{*}$ & $1.67^{*}$ \\
\hline 6150830 & BOWMANVILLE MOSTERT & $1.96^{*}$ & $1.44^{*}$ & 1.04 & 0.52 \\
\hline 6151042 & BURKETON MCLAUGHLIN & 0.45 & 1.08 & $1.73^{*}$ & $2.76^{*}$ \\
\hline 6151137 & CAMPBELLFORD & 0.32 & -0.60 & -1.16 & -1.74 \\
\hline 6153194 & HAMILTON A & -0.43 & 0.40 & 1.41 & $3.29^{*}$ \\
\hline 6153301 & HAMILTON RBG CS & 0.00 & -0.37 & -0.63 & -0.96 \\
\hline 6155878 & OSHAWA WPCP & $1.57^{*}$ & 0.82 & 0.08 & -0.97 \\
\hline 6156533 & PICTON & $-1.44^{*}$ & $-2.11^{*}$ & $-2.61^{*}$ & $-3.22^{*}$ \\
\hline 6158355 & TORONTO CITY & -0.70 & -0.59 & -0.45 & -0.19 \\
\hline 6158520 & TORONTO ELLESMERE & -1.12 & -1.24 & -1.37 & -1.58 \\
\hline 6158665 & TORONTO ISLAND A & -2.05 & -1.89 & -1.68 & -1.31 \\
\hline 6158733 & TORONTO LESTER B. PEARSON INT'L A & $-0.65^{*}$ & $-1.03^{*}$ & $-1.31^{*}$ & $-1.64^{*}$ \\
\hline 6158875 & TRENTON A & 0.82 & 1.50 & 2.10 & 3.02 \\
\hline 6166418 & PETERBOROUGH A & -0.64 & -1.03 & -1.22 & -1.39 \\
\hline
\end{tabular}

*Values with asterisks are statistically significant with $80 \%$ confidence level.

The 30 min and $2 \mathrm{~h}$ daily maximum rainfall records were analyzed as well, and the changes were pooled together, shown in Figure 5. Climate stations showing significant changes in the design rainfall intensity are plotted with triangles indicating the directions of the change. There is no conclusive regional change identified, although several climate stations with geographical proximity show the same direction of changes, e.g. the Toronto area and the area from Windsor to London show decreased changes.

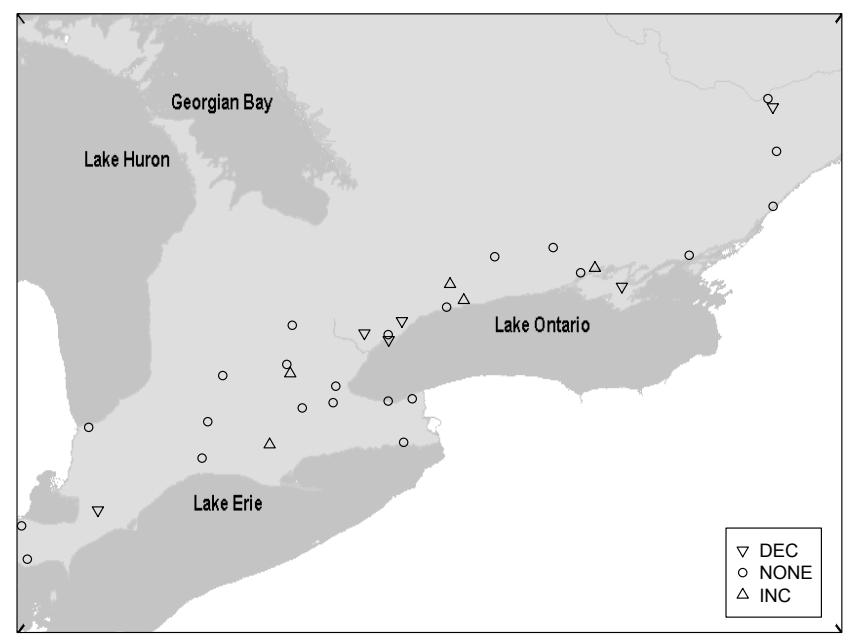

Figure 5 Design rainfall intensity changes in Southern Ontario.

Of interest is how the selection of the split year affects the design rainfall intensity changes identified. The sensitivities of the changes with respect to the split year are assessed using variable split years, enumerated from 1975 to 1990 . The result of $1 \mathrm{~h}$ daily maximum rainfall records at Delhi (climate station ID 6131983) is shown in Figure 6 . The changing rate of $2 \mathrm{y}$ return rainfall is the largest for all split years, while that of the $25 \mathrm{y}$ return rainfall is the smallest. The changing rate of the $25 \mathrm{y}$ return rainfall is not very sensitive in response to the split year, fluctuating between $1 \%$ and $1.5 \%$ per year. Most changes identified at Delhi are statistically significant, except for the two split years of 1989 and 1990. This provides strong evidence of increasing design rainfall intensities at Delhi.

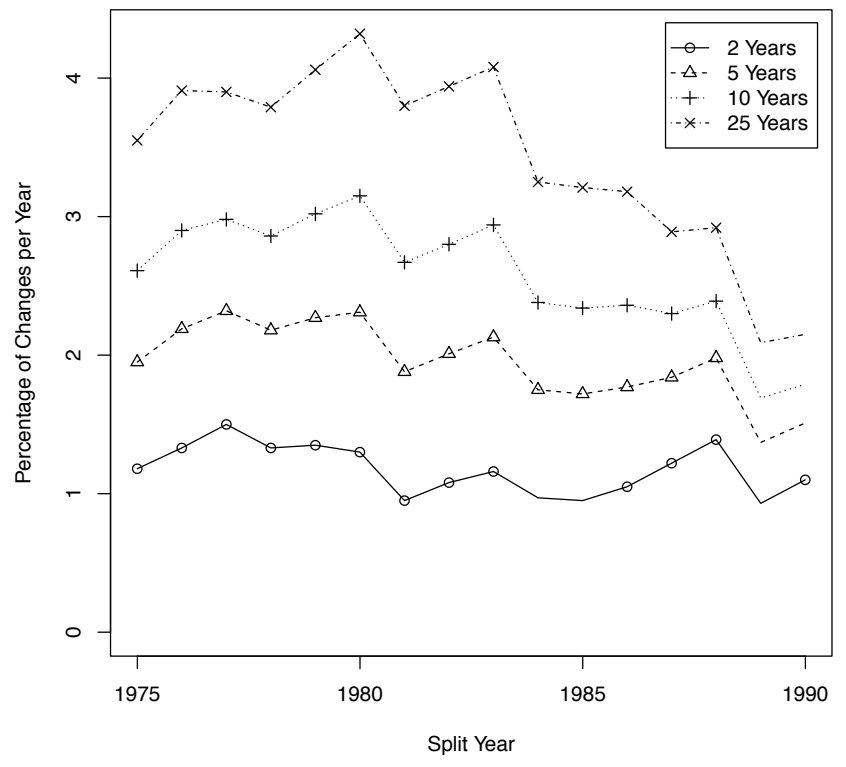

Figure 6 Sensitivity of annual changing rate and significance in respect to split year at Delhi CS, Ontario $(1 \mathrm{~h}$ duration rainfall). 
Another example at the Toronto Pearson Airport gauge (climate station ID 6158733) demonstrates a different pattern of sensitivities of the changing rates, as seen in Figure 7. The $25 \mathrm{y}$ design rainfall intensity estimate shows high decreasing rates for all split years, and is the least sensitive amongst all four return periods; the changing rate of $2 \mathrm{y}$ design rainfall intensity exhibits large sensitivity to the split year, and is always the smallest decreasing rate amongst all four return periods. The statistical significances of the changes are sensitive to the split years as well. The $5 \mathrm{y}, 10 \mathrm{y}$ and $25 \mathrm{y}$ event changes are significant when the rainfall record is split from the early 1980s until 1990, while the changes in 2 y design rainfall intensities are not statistically significant until splitting the record from the late 1980s. The sensitivity results of the statistical significance demonstrates the emergence of changes in the 1980s, and provides insights as to which period of record should be used to estimate design rainfall intensities.

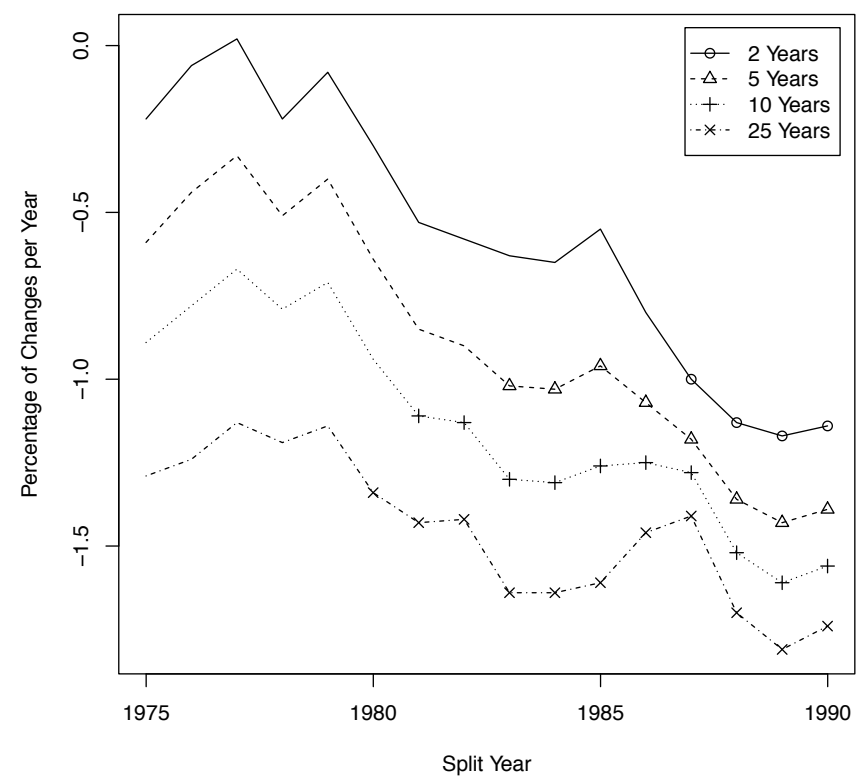

Figure 7 Sensitivity of annual changing rate and significance in respect to split year at Toronto Lester B. Pearson International Airport, Ontario (1 h duration rainfall).

Examining sensitivity analysis results at all 34 stations shows that changes in design rainfall intensity between records of two consecutive time periods are sensitive to the split year. However, the analyses of 34 stations found no consistent pattern, in terms of the trends of the changing rates or the statistical significance of changes. To conclude, the design rainfall intensity varies over time (and sometimes significantly). Therefore it is recommended to analyze the sensitivity of the design rainfall intensity in relation to the timeframe of the rainfall record being used, as an alternative to the use of the entire historical rainfall record.

\section{Use of Regional Frequency Analysis To Reduce Uncertainties}

From the foregoing conclusion, the design rainfall intensities are prone to change under the shifting climate background, and it is recommended to analyze the design rainfall intensities with respect to the timeframes of the rainfall record. Therefore, when the record employed is limited in length, the sample variance becomes considerable. In such cases, it is suggested to assign the upper confidence limit of the estimate in stormwater system design or, alternatively, to reduce the uncertainties involved in the estimates. The regional frequency analysis method is designed to reduce the uncertainties. It groups rainfall records from stations sharing statistical similarities, and estimates at-site design rainfall intensities using regional averaged cumulative frequency distribution.

The regional L-moment algorithm, which is the key method of the regional frequency analysis, is based on the index flood method. The sample L-moment ratios at each station in the group are averaged to form the regional L-moment ratios estimates, and, further, to estimate the frequency distribution parameters, as in Equations 6 and 7.

$$
\begin{aligned}
t^{R} & =\frac{\sum_{i=1}^{N} n_{i} t^{(i)}}{\sum_{i=1}^{N} n_{i}} \\
t_{r}{ }^{R} & =\frac{\sum_{i=1}^{N} n_{i} t_{r}^{(i)}}{\sum_{i=1}^{N} n_{i}}, r=3,4, \ldots
\end{aligned}
$$

where:

$$
\begin{aligned}
t, t^{(i)}= & \text { the regional and } i \text { th station sample } \mathrm{L}-\mathrm{CV} \text {, and } \\
t_{r^{\prime}} t_{r}^{(i)}= & \text { the regional and } i \text { th station } r \text { th sample } \mathrm{L}-\text { moment } \\
& \quad \text { ratio, and } \\
n_{i}= & \text { the record length }(\mathrm{y}) \text { at the } i \text { th station. }
\end{aligned}
$$

The design rainfall intensities at the ith station are estimated by the multiplication of the regional frequency distribution quantile at non-exceedance probability $F$ and the local scale factor $I_{1}^{(i)}$, which is estimated as the sample mean value in Equation 8.

$$
\widehat{Q_{l}}(F)=l_{1}^{(i)} \hat{q}(F)
$$

The statistical similarity of rainfall records from stations within a group is one of the most substantial assumptions in the regional frequency analysis. Hosking and Wallis (1997) introduced the procedures to group stations, and test the statistical homogeneity of each group. The regional frequency distribution is selected according to the L-moment ratio diagram and the goodness-of-fit measure.

To demonstrate the regional L-moment algorithm, the $1 \mathrm{~h}$ rainfall record at Kingston (climate station ID 6104175) is analyzed, and attempts are made to reduce the uncertainties involved in the $2 \mathrm{y}, 5 \mathrm{y}$ and $10 \mathrm{y}$ return event estimates. The Kingston station is grouped with geographically adjacent climate stations, as listed in Table 3. The grouping is based on the distances 
of each climate station to Lake Huron, Lake Erie and Lake Ontario as these lakes are recognized as major sources of atmospheric moisture. The heterogeneity measure of this region is evaluated as an acceptably homogeneous region. The regional frequency distribution is selected as the generalized Pareto distribution, based on the L-moment ratio diagram in Figure 8 and the goodnessof-fit measure $\left(Z^{G P A}=0.29\right)$. Table 4 shows the RMSE reduction of the design rainfall intensity estimates at the Kingston station. The uncertainties (RMSE) of the design rainfall intensity estimates at the Kingston station are reduced by $21.6 \%$ on average. Wang and McBean (2014) developed a regional frequency analysis model using PDS data in Southern Ontario.

Table 3 Climate stations grouped to improve design rainfall intensity estimate accuracy at Kingston.

\begin{tabular}{llcccc}
$\begin{array}{c}\text { Climate Station } \\
\text { ID }\end{array}$ & \multicolumn{1}{c}{ Station Name } & Lat. & Long. & Alt. (m) & $\begin{array}{c}\text { Record } \\
\text { Length }\end{array}$ \\
\hline 6104175 & KINGSTON PUMPING STATION & 44.24 & -76.48 & 76.50 & 45 \\
6150689 & BELLEVILLE & 44.15 & -77.39 & 76.20 & 41 \\
6150830 & BOWMANVILLE MOSTERT & 43.92 & -78.67 & 99.10 & 31 \\
6151137 & CAMPBELLFORD & 44.30 & -77.80 & 146.30 & 20 \\
6156533 & PICTON & 44.02 & -77.13 & 76.20 & 25 \\
6158875 & TRENTON A & 44.12 & -77.53 & 86.30 & 32 \\
\hline
\end{tabular}

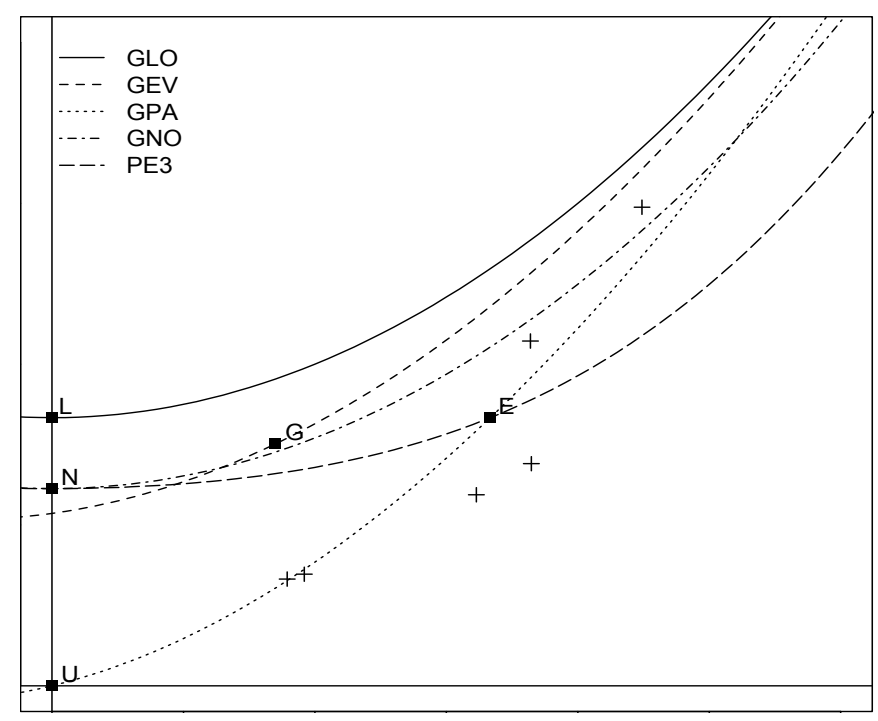

Figure 8 L-moment ratio diagram for rainfall records from stations in group with Kingston.

Table 4 Expected value and RMSE at Kingston climate station.

\begin{tabular}{lccccc}
\hline \multirow{2}{*}{ Return Period } & \multicolumn{2}{c}{ Expected Value } & \multicolumn{2}{c}{ RMSE } & \multirow{2}{*}{ RMSE Reduced } \\
& At-Site & Regional & At-Site & Regional & \\
\hline $2 \mathrm{y}$ & 21.6 & 22 & 0.93 & 0.7 & $25.80 \%$ \\
$5 \mathrm{y}$ & 27.1 & 27.1 & 1.58 & 1.04 & $36.10 \%$ \\
$10 \mathrm{y}$ & 31.5 & 30.9 & 2.38 & 1.41 & $40.80 \%$ \\
\hline
\end{tabular}

\section{Conclusions}

Three rainfall intensity models for Ontario, Canada are analyzed in several aspects including the selection of the frequency distribution, the characterization of the rainfall intensity uncertainties, the analysis of the PDS data structure, the identification of the rainfall intensity changes, and the application of regional frequency analysis.

The application of the Gumbel distribution in the AMS model is investigated and supported, which shows that the Gumbel distribution is as good as other three-parameter distributions in the modeling of rainfall values. It is recommended to use the upper confidence limit instead of the expected value of the design rainfall intensity, if the design rainfall intensities involve considerable uncertainties. It is demonstrated that, in urban stormwater system design, the PDS model is more appropriate for heavy rainfall modeling when the return period is $\leq 10 \mathrm{y}$. It is evident that rainfall intensities have been changing during the last few decades in Ontario. Spatially, changes are occurring mostly in southern Ontario, along the coasts of both Lake Erie and Lake Ontario from Windsor to Ottawa. Temporally, changes are occurring during the 1980s and 1990s, from the sensitivity analyses of the changes. In addition, it is recommended to analyze the sensitivity of the design rainfall intensity in relation to the timeframe of the rainfall record being used, as an alternative to the use of the entire historical rainfall record. It is also exhibited that the regional model using partial duration series can reduce uncertainties involved in the rainfall intensity estimates. If nearby rainfall stations have lengthy rainfall records, a regional frequency analysis model should be considered as an appropriate method to develop, to reduce uncertainties involved in rainfall intensity estimates.

\section{Acknowledgment}

The research founding provided by the Canada Research Chair program and the Ontario Research Foundation, and historical rainfall records provided by Environment Canada, are gratefully acknowledged.

\section{References}

Adamowski, K. and J. Bougadis. 2003. “Detection of Trends in Annual Extreme Rainfall." Hydrological Processes 17 (18): 3547-60.

Anderson, T. W. and D. A. Darling. 1954. "A Test of Goodness-of-Fit." Journal of the American Statistical Association 49:765-9.

Aronica, G., Freni, G., and Oliveri, E. 2005. “Uncertainty Analysis of the Influence of Rainfall Time Resolution in the Modeling of Urban Drainage Systems." Hydrological Processes 19 (5): 1055-71.

Burn, D. H. and M. A. Hag Elnur. 2002. “Detection of Hydrologic Trends and Variability." Journal of Hydrology 255 (1-4): 107-22. 
Burn, D. H. and A. Taleghani. 2013. “Estimates of Changes in Design Rainfall Values for Canada." Hydrological Processes 27 (11): 1590-9.

Coles, S., L. R. Pericchi and S. Sisson. 2003 "A Fully Probabilistic Approach to Extreme Rainfall Modeling." Journal of Hydrology 273 (1-4): 35-50.

Douglas, E., R. Vogel and C. Kroll. 2000. "Trends in Floods and Low Flows in the United States: Impact of Spatial Correlation." Journal of Hydrology 240 (1-2): 90-105.

Filliben, J. J. 1975. “The Probability Plot Correlation Coefficient Test for Normality." Technometrics 17 (1): 111-7.

Fisher, R. A. and L. H. C. Tippett. 1928. “Limiting Forms of the Frequency Distribution of the Largest or Smallest Member of a Sample." Mathematical Proceedings of the Cambridge Philosophical Society 24:180-90.

Fowler, H. J. and C. G. Kilsby. 2003. “A regional Frequency Analysis of United Kingdom Extreme Rainfall from 1961 to 2000." International Journal of Climatology 23 (11): 1313-34.

Frei, C., R. Scholl, S. Fukutome, J. Schmidli and P. L. Vidale. 2006. "Future Change of Precipitation Extremes in Europe: Intercomparison of Scenarios from Regional Climate Models." Journal of Geophysical Research 111, D06105.

García-Ruiz, J. M., J. Arnáez, S. M. White, A. Lorent and S. Beguería. 2000. “Uncertainty Assessment in the Prediction of Extreme Rainfall Events: an Example from the Central Spanish Pyrenees." Hydrological Processes 14 (5): 887-98.

Gumbel, E. 1954. Statistical Theory of Extreme Values and Some Practical Applications: A Series of Lectures. Applied Mathematics Series. Washington, DC: U. S. Government Print Office.

Hogg, W. D., D. Carr and B. Routledge. 1989. Rainfall IntensityDuration Frequency Values for Canadian Locations. Ottawa: Environment Canada, Atmospheric Environment Service.

Hosking, J. and J. Wallis. 1997. Regional Frequency Analysis: An Approach Based on L-Moments. Cambridge: Cambridge University Press.
Laurenson, E. M. 1987. "Back to Basics on Flood Frequency Analysis." Transactions of the Institution of Engineers, Australia Civil Engineering 29 (2): 47-53.

Ngongondo, C., C.-Y. Xu, L. Tallaksen, B. Alemaw and T. Chirwa. 2011. “Regional Frequency Analysis of Rainfall Extremes in Southern Malawi Using the Index Rainfall and L-moments Approaches." Stochastic Environmental Research and Risk Assessment 25: 939-55.

Semadeni-Davies, A., C. Hernebring, G. Svensson and L.-G. Gustafsson. 2008. "The Impacts of Climate Change and Urbanisation on Drainage in Helsingborg, Sweden: Combined Sewer System." Journal of Hydrology 350 (1-2): 100-13.

Sveinsson, O., J. Salas and D. Boes. 2002. “Regional Frequency Analysis of Extreme Precipitation in Northeastern Colorado and Fort Collins Flood of 1997." Journal of Hydrologic Engineering 7 (1): 49-63.

Vincent, L. A., and Mekis, É. 2006. “Changes in Daily and Extreme Temperature and Precipitation Indices for Canada over the Twentieth Century." Atmosphere-Ocean 44 (2): 177-93.

Wang, Y. and E. A. McBean. 2013. “Uncertainty Characterization of Rainfall Inputs Used in the Design of Storm Sewer Infrastructure. Journal of Water Management Modeling C367. doi:10.14796/JWMM.C367

Wang, Y. and E. A. McBean. Forthcoming. "Identification of Design Rainfall Changes Using Regional Frequency Analysis: A Case Study in Ontario, Canada."

Zhai, P., Sun, A., Ren, F., Liu, X., Gao, B., and Zhang, Q. 1999. “Changes of Climate Extremes in China." Climatic Change 42 203-18.

Zhang, X., W. D. Hogg and É. Mekis. 2001. "Spatial and Temporal Characteristics of Heavy Precipitation Events Over Canada." Journal of Climate 14 (9): 1923-36. 